\title{
Sustained intraocular pressure reduction throughout the day with travoprost ophthalmic solution $0.004 \%$
}

This article was published in the following Dove Press journal:

Clinical Ophthalmology

28 March 2012

Number of times this article has been viewed

\author{
Harvey B Dubiner' \\ Robert Noecker ${ }^{2}$ \\ 'Clayton Eye Center, Morrow, GA; \\ ${ }^{2}$ Ophthalmic Consultants of \\ Connecticut, Fairfield, CT, USA
}

Background: The purpose of this study was to characterize intraocular pressure (IOP) reduction throughout the day with travoprost ophthalmic solution $0.004 \%$ dosed once daily in the evening.

Methods: The results of seven published, randomized clinical trials including at least one arm in which travoprost $0.004 \%$ was dosed once daily in the evening were integrated. Means (and standard deviations) of mean baseline and on-treatment IOP, as well as mean IOP reduction and mean percent IOP reduction at 0800, 1000, and 1600 hours at weeks 2 and 12 were calculated.

Results: From a mean baseline IOP ranging from 25.0 to $27.2 \mathrm{mmHg}$, mean IOP on treatment ranged from 17.4 to $18.8 \mathrm{mmHg}$ across all visits and time points. Mean IOP reductions from baseline ranged from 7.6 to $8.4 \mathrm{mmHg}$ across visits and time points, representing a mean IOP reduction of $30 \%$. Results of the safety analysis were consistent with the results from the individual studies for travoprost ophthalmic solution $0.004 \%$, with ocular hyperemia being the most common side effect.

Conclusion: Travoprost $0.004 \%$ dosed once daily in the evening provides sustained IOP reduction throughout the 24-hour dosing interval in subjects with ocular hypertension or open-angle glaucoma. No reduction of IOP-lowering efficacy was observed at the 1600-hour time point which approached the end of the dosing interval.

Keywords: travoprost ophthalmic solution $0.004 \%$, intraocular pressure reduction

\section{Introduction}

Intraocular pressure (IOP) is an important risk factor for the development and progression of glaucoma. In recent years, The Ocular Hypertension Treatment Trial has demonstrated that IOP reduction can prevent the development of glaucoma among individuals with ocular hypertension ${ }^{1,2}$ and can reduce the risk of glaucoma progression among subjects with both normal ${ }^{3-5}$ and elevated IOP. ${ }^{4}$ The impact of both short-term and long-term IOP variability on progression risk has also been explored, with many ${ }^{6-10}$ (but not all) ${ }^{11,12}$ studies finding a positive relationship between greater IOP variability and higher rates of glaucomatous progression or development.

The possibility that IOP variability may be a risk factor for glaucoma progression has stimulated a growing interest in the clinical evaluation and characterization of diurnal variability. A number of recent studies have challenged traditional thinking about IOP behavior. Historically, circadian IOP was believed to reach its peak values in the morning hours around the time of waking. These studies were typically conducted with subjects in the sitting position. When the physiologically more appropriate habitual
Correspondence: Harvey B Dubiner Clayton Eye Center, 1000 Corporate Center Drive, Suite 102, Morrow, GA 30260, USA

Tel +l 4045209225

Fax +l 7709684008

Email glaucdocatl@mindspring.com 
position was studied, with subjects sitting during daytime hours and supine at night, a different IOP pattern emerged in which IOP peaked at night during sleeping hours in both healthy ${ }^{13-17}$ and glaucomatous individuals. ${ }^{13,17}$ Additionally, diurnal IOP patterns may not be conserved from day to day, ${ }^{18,19}$ and IOP fluctuations in fellow-eye pairs may be less well correlated than previously believed. . $^{160-22}$

Despite this growing body of research suggesting that IOP variability may predict future glaucoma progression, routine evaluation of circadian IOP in clinical practice remains a significant clinical challenge. Unlike for blood pressure or blood glucose levels, there are no inexpensive, easy-to-use devices for home or self-assessment of IOP. IOP measurement remains an in-office assessment, rendering characterization of individual IOP variability both expensive and time-consuming. Adding to the challenge of clinical IOP variability is the observation that most subjects experience their peak IOP after typical office hours. ${ }^{13,17}$

In light of the realization that consistent IOP reduction throughout the 24-hour period is important in preventing glaucomatous progression, coupled with the difficulties of assessing 24-hour IOP in routine clinical practice, there remains a need for therapy that provides consistent IOP reduction throughout the dosing interval with minimal peak and trough variability.

Travoprost ophthalmic solution $0.004 \%$ is a prostaglandin analog available throughout the global marketplace and indicated for IOP reduction in subjects with open-angle glaucoma or ocular hypertension. Travoprost ophthalmic solution has been formulated with a variety of preservatives. This paper reports the results of an integrated analysis of seven randomized clinical trials containing at least one travoprost $0.004 \%$ monotherapy arm, ${ }^{23-29}$ the goal of which is to characterize the consistency of IOP reduction throughout the travoprost dosing interval.

\section{Materials and methods}

This integrated analysis comprised data from seven peerreviewed, published, prospective randomized trials. Each study was conducted at multiple clinical centers throughout the world, and each was reviewed and approved by the appropriate ethics committees. Because this integrated analysis utilized study-level data rather than subject-level data, no individual data were accessed or analyzed, and no further ethics committee approval was required.

The seven studies included in this integrated analysis were selected based on shared characteristics. All but one were registration trials and each was conducted according to the rigorous and robust methodology required by the US Food and Drug Administration and other international drug approval bodies; the sole nonregistration trial was a duration of action study conducted to registration trial standards. Phase IV studies were excluded because the design of these trials differs from those of the registration trials (ie, sample size, endpoints, and inclusion and exclusion criteria). Six of the included studies were registration trials for travoprost preserved with either benzalkonium chloride (Travatan ${ }^{\circledR}$, Alcon Laboratories, Fort Worth, TX) or sofZia ${ }^{\circledR}$ (Travatan $Z^{\circledR}$, Alcon); one was a registration trial for a travoprost-timolol fixed combination (DuoTrav ${ }^{\circledR}$, Alcon) that included a travoprost monotherapy arm in a contribution of elements design. All seven studies utilized travoprost in strict accordance with its labeling, employed identical dosing regimens, and all had previously been published. Because of their shared purpose and design, the subjects enrolled in these studies met similar eligibility criteria and are thus a substantially homogenous population taken as a whole. Table 1 lists the key design characteristics of the seven studies included in this integrated analysis.

The primary objective of this study was to characterize the consistency of IOP reduction achieved with travoprost $0.004 \%$ dosed once daily throughout the 24-hour dosing interval. The primary outcome of this descriptive analysis was the mean percent change from baseline in IOP at week 2 and week 12 at 0800, 1000 and 1600 hours $(0900,1100$, and 1600 in European studies), which represent the latter half of the 24-hour dosing interval for travoprost. Not every study in the integrated analysis included IOP assessments at each of these visits and time points; as such, the sample size at each visit and time point was not constant.

For the mean and standard deviation, we exploited the fact that both of these parameters can be calculated for any collection of data using the sample size, the sum of the data values, and the sum of the squares of the data values. For a sample consisting of $\mathrm{k}$ values of the variable $\mathrm{x}$, which we will denote as $\mathrm{x}_{1}, \mathrm{x}_{2}, \ldots \mathrm{x}_{\mathrm{k}}$, we have

$$
\bar{X}=\left(\sum_{i=1}^{k} x_{i}\right) / k
$$

and

$$
\mathrm{SD}=\left[1 /(\mathrm{k}-1) \times\left(\left(\sum_{\mathrm{i}=1}^{\mathrm{k}} \mathrm{x}_{\mathrm{i}}^{2}\right)-(\mathrm{T})^{2} / \mathrm{k}\right)\right]^{1 / 2}
$$

where $\mathrm{T}$ denotes the sum of the $\mathrm{x}$ values, easily obtained by multiplying the sample mean by the sample size. 
Table I Key design features of the seven studies included in this integrated analysis

\begin{tabular}{|c|c|c|c|}
\hline Reference & n, Travoprost $0.004 \%$ arm(s) ITT/PP & Study eye IOP criteria & Visits and time points \\
\hline Netland et $\mathrm{al}^{29}$ & $197 / 187$ & $\begin{array}{l}24-36 \mathrm{mmHg} \text { at } 0800 \text { and } 21-36 \mathrm{mmHg} \\
\text { at } 1000 \text { and } 1600 \text { on two separate visits }\end{array}$ & $\begin{array}{l}0800,1000 \text {, and } 1600 \text { at baseline, } \\
\text { week } 2 \text {, and week } 12\end{array}$ \\
\hline Gross et $\mathrm{a}^{27}$ & $\begin{array}{l}\text { 52/52 Travoprost } \\
\text { 54/54 Travoprost with sofZia }{ }^{\circledR}\end{array}$ & $24-36 \mathrm{mmHg}$ at 0800 & 0800 at baseline and week 2 \\
\hline Lewis et $\mathrm{a}^{28}$ & $\begin{array}{l}\text { 341/339 Travoprost } \\
\text { 338/322 Travoprost with sofZia }\end{array}$ & $\begin{array}{l}24-36 \mathrm{mmHg} \text { at } 0800 \text { and } 21-36 \mathrm{mmHg} \\
\text { at } 1000 \text { and } 1600 \text { on two separate visits }\end{array}$ & $\begin{array}{l}0800,1000 \text {, and } 1600 \text { at baseline, } \\
\text { week } 2 \text {, and week } 12\end{array}$ \\
\hline Goldberg et $\mathrm{al}^{26}$ & $197 / 176$ & $\begin{array}{l}24-36 \mathrm{mmHg} \text { at } 0900 \text { and } 21-36 \mathrm{mmHg} \\
\text { at } 1100 \text { and } 1600 \text { on two separate visits }\end{array}$ & $\begin{array}{l}0900,1100 \text {, and } 1600 \text { at baseline, } \\
\text { week } 2 \text {, and week } 12\end{array}$ \\
\hline Barnebey et $\mathrm{al}^{23}$ & $84 / 77$ & $\begin{array}{l}\geq 26 \mathrm{mmHg} \text { at } 0800 \text { on two separate visits, } \\
\geq 24 \mathrm{mmHg} \text { at } 1000 \text { on one visit, and } \\
\geq 22 \mathrm{mmHg} \text { at } 1600 \text { on one visit }\end{array}$ & $\begin{array}{l}0800,1000 \text {, and } 1600 \text { at baseline, } \\
\text { week } 2 \text {, and week } 12\end{array}$ \\
\hline Fellman et $\mathrm{a}^{24}$ & $197 / 179$ & $24-36 \mathrm{mmHg}$ at 0800 on 2 separate visits & $\begin{array}{l}0800,1000 \text { and } 1600 \text { at baseline, } \\
\text { week } 2 \text { and week } 12\end{array}$ \\
\hline Gandolfi et $\mathrm{al}^{25}$ & $\begin{array}{l}\text { 185/177 Travoprost } \\
\text { I85/176 Travoprost with sofZia }\end{array}$ & $\begin{array}{l}24-36 \mathrm{mmHg} \text { at } 0900 \text { and } 2 \mathrm{I}-36 \text { at } \mathrm{I} 100 \\
\text { and } 1600 \text { on two separate visits }\end{array}$ & $\begin{array}{l}0900,1100 \text { and } 1600 \text { at baseline, } \\
\text { week } 2 \text { and week } 12\end{array}$ \\
\hline
\end{tabular}

Abbreviations: ITT, intent to treat; PP, per protocol; IOP, intraocular pressure.

For each study that contributed data to the integrated summary, working backwards from the sample size, mean, and standard deviation that had been provided, the formulae above were applied to calculate the sum of the data values and the sum of the squares of the data values for the study. These sums (and the sample sizes) were then added across all of the contributing studies in order to obtain the overall sample size, the sum of the combined data, and the sum of squares of the combined data. Applying the formulae above once again, the mean and standard deviation of the combined data were then obtained. Both the intent-to-treat and per protocol data sets were analyzed, and the results of both these analyses were similar. The per protocol data set is presented in this paper, because this integrated analysis is not a comparative study, and the per protocol data set is limited to those who were both randomized to and received travoprost $0.004 \%$ as study medication, and is therefore a more robust estimate of the efficacy of travoprost.

\section{Results}

\section{Subject disposition and demographics}

The integrated analysis consisted of data collected from a total of 1669 subjects, all of whom were included in the safety analysis. The intent-to-treat analysis included 1645 subjects who attended at least one on-treatment assessment. The per protocol analysis included 1563 subjects. Common reasons that subjects were excluded from the per protocol data set included failure to achieve required washout IOP level, use of excluded concomitant medications, nonadherence with study medication dosing, and other violations of eligibility criteria. Demographic and baseline characteristics of the integrated per protocol study population are given in Table 2 .

\section{Source data}

The mean ( \pm standard deviation) IOP at each visit and time point in the travoprost arms of each of the seven studies included in this integrated analysis are given in Table 3 . These are the values from the per protocol analyses and therefore may differ from values in the published study reports which used intent-to-treat analyses in keeping with the design and statistical goals of those studies.

\section{Consistency of IOP reduction}

The baseline IOP and mean IOP, mean IOP reduction, and mean percent IOP reduction at each on-treatment visit and time point in the per protocol data set are given in Table 4. From mean baseline IOP ranging from 25.0 to $27.2 \mathrm{mmHg}$, mean IOP on treatment ranged from 17.4 to $18.8 \mathrm{mmHg}$ across all visits and time points. Mean IOP

Table 2 Demographics and baseline characteristics of subjects in the per protocol data set $(n=1563)$ of the integrated analysis

\begin{tabular}{|c|c|}
\hline Age (years), mean (standard deviation) & $63.1 \pm 11.3$ \\
\hline \multicolumn{2}{|l|}{ Gender, n (\%) } \\
\hline Male & $719(46.0)$ \\
\hline Female & $844(54.0)$ \\
\hline \multicolumn{2}{|l|}{ Ethnicity, n (\%) } \\
\hline Caucasian & $1130(72.3)$ \\
\hline Black & $247(15.8)$ \\
\hline Hispanic & $89(5.7)$ \\
\hline Asian & $4 \mathrm{I}(2.6)$ \\
\hline Other & $56(3.6)$ \\
\hline \multicolumn{2}{|l|}{ Diagnosis, n (\%) } \\
\hline Open-angle glaucoma & $962(61.5)$ \\
\hline Ocular hypertension & $549(35.1)$ \\
\hline Pigmentary glaucoma & $27(1.7)$ \\
\hline Pseudoexfoliation glaucoma & $25(1.6)$ \\
\hline
\end{tabular}


Table 3 Mean ( \pm standard deviation) intraocular pressure $(\mathrm{mmHg})$ at each visit and time point in the travoprost arms of the seven studies included in this integrated analysis (per protocol data set)

\begin{tabular}{|c|c|c|c|c|c|c|c|c|c|}
\hline \multirow[t]{2}{*}{ Reference } & \multicolumn{3}{|l|}{ Baseline } & \multicolumn{3}{|l|}{ Week 2} & \multicolumn{3}{|l|}{ Week I 2} \\
\hline & 0800 & 1000 & 1600 & 0800 & 1000 & 1600 & 0800 & 1000 & 1600 \\
\hline Netland et $\mathrm{al}^{29}$ & $26.8(2.6)$ & $25.2(2.8)$ & $24.6(2.8)$ & $18.8(3.6)$ & $17.52(3.5)$ & $17.3(3.0)$ & $18.7(3.3)$ & I7.3 (3.7) & $17.6(3.1)$ \\
\hline \multicolumn{10}{|l|}{ Gross et $\mathrm{al}^{27}$} \\
\hline Travoprost & $27.1(2.9)$ & - & - & I8.5 (4.0) & - & - & - & - & - \\
\hline $\begin{array}{l}\text { Travoprost } \\
\text { with sofZia }{ }^{\circledR}\end{array}$ & $26.9(3.2)$ & - & - & $18.7(4.2)$ & - & - & - & - & - \\
\hline \multicolumn{10}{|l|}{ Lewis et $\mathrm{a}^{28}$} \\
\hline Travoprost & $27.2(2.7)$ & $25.6(2.9)$ & $24.9(2.9)$ & $18.8(3.5)$ & $17.9(3.6)$ & 17.5 & $18.8(3.6)$ & I7.7 (3.3) & $17.2(3.1)$ \\
\hline $\begin{array}{l}\text { Travoprost } \\
\text { with sofZia }{ }^{\circledR}\end{array}$ & $27.0(2.3)$ & $25.5(2.7)$ & $24.8(2.7)$ & $18.5(2.9)$ & I7.7 (3.3) & $17.3(3.1)$ & $18.7(3.5)$ & I $7.7(3.2)$ & I $7.3(3.2)$ \\
\hline Goldberg et $\mathrm{al}^{26}$ & $27.4(2.8)$ & $26.5(2.9)$ & $25.6(3.0)$ & $18.9(3.4)$ & 17.9 (3.3) & $17.4(3.3)$ & $18.5(3.4)$ & 17.6 & $16.8(2.9)$ \\
\hline Barnebey et $\mathrm{a}^{23}$ & $29.8(2.7)$ & $28.2(3.1)$ & $26.9(3.5)$ & 20.6 (3.9) & $19.0(3.8)$ & $18.6(3.6)$ & $20.6(3.7)$ & $19.2(3.2)$ & $18.7(3.2)$ \\
\hline Fellman et $\mathrm{al}^{24}$ & $27.3(3.0)$ & $25.7(3.4)$ & $25.1(3.0)$ & $19.3(3.7)$ & I8.I (3.4) & $17.6(3.2)$ & 19.7 (3.9) & 18.5 & 18.0 \\
\hline Gandolfi et $\mathrm{al}^{25}$ & $26.9(2.6)$ & $25.6(2.9)$ & $24.8(2.8)$ & I8.I (3.5) & $17.8(3.5)$ & I7.I (3.2) & 18.0 & $17.4(3.4)$ & 17.0 \\
\hline
\end{tabular}

Note: All studies evaluated travoprost (preserved with benzalkonium chloride) unless otherwise stated.

reductions from baseline ranged from 7.6 to $8.4 \mathrm{mmHg}$ across visits and time points, with less than a $1 \mathrm{mmHg}$ difference between 0800 and 1600 time points at both weeks 2 and 12 . Mean percent IOP reductions were remarkably consistent throughout the day. Mean IOP was lowered by at least $30 \%$ at every visit and time point, including the 1600-hour time point, 20 hours into the travoprost dosing interval (Figure 1).

\section{Safety}

Among the 1669 subjects in this integrated analysis, travoprost was generally well tolerated, and most adverse events were mild to moderate in severity and required no intervention. The discontinuation rate due to all adverse events was $3.2 \%$ (53 of 1666 subjects for whom discontinuation data were available). The adverse events seen in $1 \%$ or more of subjects are given in Table 5 . Ocular hyperemia was the most common adverse event. In three of the studies, ocular hyperemia was identified as an adverse event if the study physician judged that it had increased by one or more points on a four-point (0-3) scale; in the remaining four studies, ocular hyperemia was identified as an adverse event if the subject reported it. The rate of physician-reported ocular hyperemia (increase of one unit on a four-point scale) was $38.8 \%$ (232/598 subjects), while the rate of subject-reported ocular hyperemia was $8.5 \%$ (91/1071 subjects). Other common adverse events included ocular itching, discomfort, pain, dry eye, foreign body sensation, and keratitis, each of which occurred at an incidence between $1 \%-5 \%$.

Table 4 Mean IOP at baseline and mean IOP, mean IOP reduction, and percent mean IOP reduction at each visit and time point in the per protocol data set of the integrated analysis

\begin{tabular}{|c|c|c|c|c|c|c|c|c|c|}
\hline & \multicolumn{3}{|c|}{ Baseline } & \multicolumn{3}{|c|}{ Week 2} & \multicolumn{3}{|c|}{ Week I2 } \\
\hline & 0800 & 1000 & 1600 & 0800 & 1000 & 1600 & 0800 & 1000 & 1600 \\
\hline \multicolumn{10}{|c|}{$\mathrm{IOP}, \mathrm{mmHg}$} \\
\hline Mean & 27.2 & 25.8 & 25.0 & 18.8 & 17.9 & 17.4 & 18.8 & 17.8 & 17.4 \\
\hline SD & 2.7 & 3.0 & 2.9 & 3.5 & 3.5 & 3.3 & 3.6 & 3.4 & 3.2 \\
\hline $\mathrm{n}$ & 1563 & 1456 & 1457 & 1539 & 1436 & 1435 & 1376 & 1375 & 1375 \\
\hline \multicolumn{10}{|c|}{ IOP reduction, mmHg } \\
\hline Mean & - & - & - & -8.4 & -7.9 & -7.6 & -8.5 & -7.9 & -7.6 \\
\hline SD & - & - & - & 3.3 & 3.5 & 3.4 & 3.3 & 3.5 & 3.3 \\
\hline $\mathrm{n}$ & - & - & - & 1539 & 1463 & 1435 & 1376 & 1375 & 1375 \\
\hline \multicolumn{10}{|c|}{ Percent IOP reduction, \% } \\
\hline Mean & - & - & - & -30.8 & -30.4 & -30.0 & -30.9 & -30.5 & -30.1 \\
\hline SD & - & - & - & 11.3 & 12.3 & 11.9 & 11.5 & 12.0 & 11.8 \\
\hline $\mathrm{n}$ & - & - & - & 1539 & 1436 & 1435 & 1376 & 1375 & 1375 \\
\hline
\end{tabular}

Abbreviations: IOP, intraocular pressure; SD, standard deviation. 


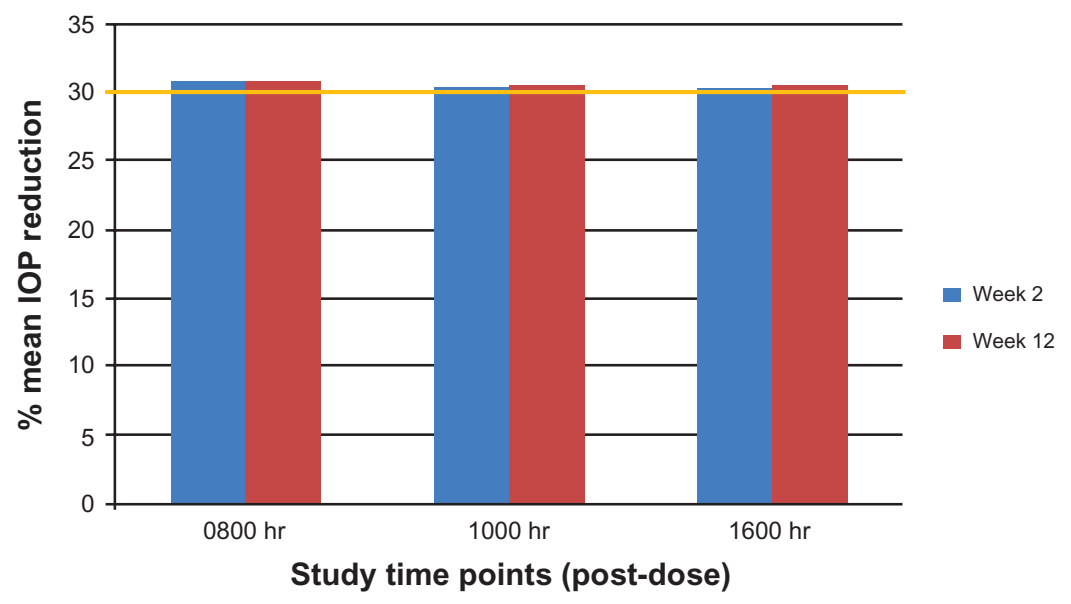

Figure I Mean percent intraocular pressure reduction by visit and time point.

\section{Discussion}

The current study demonstrates that travoprost ophthalmic solution $0.004 \%$ provides a sustained $30 \%$ IOP reduction. In this integrated analysis, travoprost exhibited no reduction of effect even in the latter portion of the 24-hour period. These results are consistent with the individual results of the included studies but provide a more robust estimate of the circadian IOP-lowering profile of travoprost in a sample of over 1500 subjects.

Consistent reduction of IOP throughout the 24-hour period is emerging as an important consideration in the management of glaucoma. An early study by Asrani et al brought attention to the role of IOP fluctuation in glaucoma progression. ${ }^{6}$ In that study, glaucoma subjects who had undergone diurnal IOP assessment several years previously, using a home tonometer initially designed for research applications, were assessed retrospectively for subsequent visual field progression. Subjects in the upper 25th percentile of diurnal IOP range were significantly more likely to experience glaucomatous progression compared with those in the lower 25th percentile, independent of mean IOP. More recently, a multicenter chart review found that the risk of

Table 5 Adverse events occurring at a rate of I\% or greater in the integrated analysis $(n=1669$ subjects with safety data)

\begin{tabular}{ll}
\hline & $\mathbf{n}(\%)$ \\
\hline Ocular hyperemia, physician-reported $(\mathrm{n}=598 / 1669)$ & $232(38.8)$ \\
Ocular hyperemia, subject-reported $(\mathrm{n}=107 \mathrm{I} / \mathrm{I669)}$ & $91(8.5)$ \\
Ocular pruritus & $69(4.1)$ \\
Ocular discomfort & $51(3.1)$ \\
Ocular pain & $35(2.1)$ \\
Dry eye & $33(2.0)$ \\
Foreign body sensation & $33(2.0)$ \\
Keratitis & $23(1.4)$ \\
\hline
\end{tabular}

progression increased by approximately $4-5$-fold with each one unit increase in the standard deviation of intervisit IOP. ${ }^{7}$ While essentially no prospective studies have been designed specifically to evaluate the significance of diurnal variability on glaucoma progression, its importance can be inferred from analyses of many recent clinical trials. Post hoc analyses of cohorts of patients from both the Advanced Glaucoma Intervention Study ${ }^{8,9}$ and the Collaborative Initial Glaucoma Treatment Study ${ }^{10}$ data sets found associations between IOP variability and the risk of visual field progression. In contrast, the Early Manifest Glaucoma Study and Malmo Ocular Hypertension Study data sets did not confirm this association. ${ }^{11,12}$ One potential explanation for these disparate findings is that IOP variability may be less important in early-stage glaucoma compared with later-stage glaucoma. ${ }^{30}$ Given these reports, and despite the lack of appropriately designed and adequately powered studies directly exploring this topic, a preponderance of evidence to date suggests that IOP variability is relevant in the discussion of risk factors for glaucoma progression.

Our understanding of both diurnal IOP variability and long-term IOP fluctuation is limited by the paucity of studies on these topics, which in turn is attributable to the lack of home tonometry and the expense of collecting the many IOP measurements necessary to characterize IOP behavior over time. Peak IOP has recently been identified as an important IOP parameter associated with disease progression..$^{31}$ IOP peaks at night when subjects are sleeping supine, ${ }^{13-17}$ making it impractical to determine peak IOP in routine clinical practice. Moreover, peak IOP may not occur at the same time on each day, because IOP patterns in both healthy and glaucomatous individuals are not highly conserved from day to day. ${ }^{18,19}$ Thus, assessing the efficacy of drug therapy in 
reducing an individual's peak IOP is not currently feasible in clinical practice. In light of this important limitation, a drug that consistently lowers IOP at all time points throughout the dosing interval would have value in reducing both the diurnal IOP variability and the long-term fluctuation of IOP in subjects with open-angle glaucoma or ocular hypertension. The current analysis demonstrates that travoprost $0.004 \%$ dosed once daily in the evening provides a sustained mean IOP reduction of $30 \%$ throughout the day. Furthermore, this efficacy was consistent, being comparable at both week 2 and week 12 in the integrated analysis of seven clinical trials.

The clinical significance of a $30 \%$ IOP reduction is based on observations from major clinical trials. In the Ocular Hypertension Treatment Study, a 20\% IOP reduction significantly reduced but did not eliminate the rate of conversion from ocular hypertension to open-angle glaucoma. ${ }^{1}$ Similarly, an average $25 \%$ IOP reduction in the Early Manifest Glaucoma Trial significantly reduced but did not eliminate progression of manifest glaucoma. ${ }^{4}$ In contrast, subjects in both the medically and surgically treated arms of the Collaborative Initial Glaucoma Treatment Study demonstrated long-term stability of glaucoma, with mean IOP reductions of approximately $35 \%$ and $48 \%$, respectively. ${ }^{32}$ These studies, taken together, suggest that the relationship between IOP reduction and glaucoma may take the form of a threshold effect; $25 \%$ reduction is not enough, and in excess of $35 \%$ may not be necessary for subjects with early or moderate open-angle glaucoma. We lack data on IOP reductions between $25 \%-35 \%$ to identify more precisely the optimal threshold IOP reduction.

The sustained 30\% IOP reduction from baseline that can be achieved with travoprost monotherapy is a reasonable therapeutic target for most subjects with open-angle glaucoma or ocular hypertension. Some subjects, such as those with higher IOP, more advanced disease, or high-risk factors such as pseudoexfoliation, may require greater IOP reductions to achieve disease stability.

This analysis is strengthened by its large sample size, which permits robust estimation of both the efficacy and safety profiles of travoprost. It is also strengthened by inclusion of studies conducted to registration trial standards, thus ensuring that each study was adequately designed and powered and conducted under the strictest of protocols, each of which shared important methodological similarities such as eligibility criteria and IOP assessment. These key design features assure the integrity of both the efficacy and safety data collected in each study. The analysis is limited by the lack of nocturnal IOP data, which are not a standard component of registration trials for IOP-lowering medications. The data in this analysis cover only half the dosing interval, but it is the latter half, which represents a worst-case scenario when presumably efficacy approaches a trough effect.

This integrated analysis, with its large sample size for a prostaglandin analog study, allows a fuller characterization of the safety profile of travoprost. The safety profile identified in this analysis was consistent with the results of the individual studies, with hyperemia being the most common adverse event.

In summary, this integrated analysis demonstrates that travoprost $0.004 \%$ dosed once daily in the evening provides sustained 30\% mean IOP reduction throughout the day in subjects with ocular hypertension or open-angle glaucoma. No significant loss of IOP-lowering efficacy was observed at the 1600-hour time point, which approached the end of the dosing interval.

\section{Disclosure}

Assistance with data analysis and preparation of this manuscript was provided by Douglas A Hubatsch (Global Medical Affairs, Alcon Laboratories Inc), Howard M Proskin (President, Howard M Proskin and Associates Inc), and Tony Realini.

\section{References}

1. Kass MA, Heuer DK, Higginbotham EJ, et al. The Ocular Hypertension Treatment Study: a randomized trial determines that topical ocular hypotensive medication delays or prevents the onset of primary openangle glaucoma. Arch Ophthalmol. 2002;120:701-713.

2. Kass MA, Gordon MO, Gao F, et al. Delaying treatment of ocular hypertension: the ocular hypertension treatment study. Arch Ophthalmol. 2010;128:276-287.

3. Collaborative Normal-Tension Glaucoma Study Group. The effectiveness of intraocular pressure reduction in the treatment of normal-tension glaucoma. Am J Ophthalmol. 1998;126:498-505.

4. Heijl A, Leske MC, Bengtsson B, et al. Reduction of intraocular pressure and glaucoma progression: results from the Early Manifest Glaucoma Trial. Arch Ophthalmol. 2002;120:1268-1279.

5. Collaborative Normal-Tension Glaucoma Study Group. Comparison of glaucomatous progression between untreated patients with normaltension glaucoma and patients with therapeutically reduced intraocular pressures. Am J Ophthalmol. 1998;126:487-497.

6. Asrani S, Zeimer R, Wilensky J, et al. Large diurnal fluctuations in intraocular pressure are an independent risk factor in patients with glaucoma. J Glaucoma. 2000;9:134-142.

7. Lee PP, Walt JW, Rosenblatt LC, et al. Association between intraocular pressure variation and glaucoma progression: data from a United States chart review. Am J Ophthalmol. 2007;144:901-907.

8. Caprioli J, Coleman AL. Intraocular pressure fluctuation a risk factor for visual field progression at low intraocular pressures in the advanced glaucoma intervention study. Ophthalmology. 2008;115:1123-1129. e3.

9. Nouri-Mahdavi K, Hoffman D, Coleman AL, et al. Predictive factors for glaucomatous visual field progression in the Advanced Glaucoma Intervention Study. Ophthalmology. 2004;111:1627-1635.

10. Musch DC, Gillespie BW, Niziol LM, et al. Intraocular pressure control and long-term visual field loss in the Collaborative Initial Glaucoma Treatment Study. Ophthalmology. 2011;118:1766-1773. 
11. Bengtsson B, Leske MC, Hyman L, Heijl A. Fluctuation of intraocular pressure and glaucoma progression in the early manifest glaucoma trial. Ophthalmology. 2007;114:205-209.

12. Bengtsson B, Heijl A. Diurnal IOP fluctuation: not an independent risk factor for glaucomatous visual field loss in high-risk ocular hypertension. Graefes Arch Clin Exp Ophthalmol. 2005;243:513-518.

13. Liu JH, Zhang X, Kripke DF, Weinreb RN. Twenty-four-hour intraocular pressure pattern associated with early glaucomatous changes. Invest Ophthalmol Vis Sci. 2003;44:1586-1590.

14. Liu JH, Bouligny RP, Kripke DF, Weinreb RN. Nocturnal elevation of intraocular pressure is detectable in the sitting position. Invest Ophthalmol Vis Sci. 2003;44:4439-4442.

15. Liu JH, Kripke DF, Twa MD, et al. Twenty-four-hour pattern of intraocular pressure in the aging population. Invest Ophthalmol Vis Sci. 1999;40:2912-2917.

16. Liu JH, Sit AJ, Weinreb RN. Variation of 24-hour intraocular pressure in healthy individuals: right eye versus left eye. Ophthalmology. 2005;112:1670-1675.

17. Mosaed S, Liu JH, Weinreb RN. Correlation between office and peak nocturnal intraocular pressures in healthy subjects and glaucoma patients. Am J Ophthalmol. 2005;139:320-324.

18. Realini T, Weinreb N, Wisniewski S. Short-term repeatability of diurnal intraocular pressure patterns in glaucomatous individuals. Ophthalmology. 2011;118:47-51.

19. Realini T, Weinreb RN, Wisniewski SR. Diurnal intraocular pressure patterns are not repeatable in the short term in healthy individuals. Ophthalmology. 2010;117:1700-1704.

20. Realini T, Barber L, Burton D. Frequency of asymmetric intraocular pressure fluctuations among patients with and without glaucoma. Ophthalmology. 2002;109:1367-1371.

21. Sit AJ, Liu JH, Weinreb RN. Asymmetry of right versus left intraocular pressures over 24 hours in glaucoma patients. Ophthalmology. 2006;113:425-430.

22. Bhorade AM, Gordon MO, Wilson B, et al. Variability of intraocular pressure measurements in observation participants in the ocular hypertension treatment study. Ophthalmology. 2009;116:717-724.
23. Barnebey HS, Orengo-Nania S, Flowers BE, et al. The safety and efficacy of travoprost $0.004 \%$ /timolol $0.5 \%$ fixed combination ophthalmic solution. Am J Ophthalmol. 2005;140:1-7.

24. Fellman RL, Sullivan EK, Ratliff M, et al. Comparison of travoprost $0.0015 \%$ and $0.004 \%$ with timolol $0.5 \%$ in patients with elevated intraocular pressure: a 6-month, masked, multicenter trial. Ophthalmology. 2002;109:998-1008.

25. Gandolfi S, Paredes T, Goldberg I, et al. Comparison of a travoprost BAK-free formulation preserved with polyquaternium-1 with BAKpreserved travoprost in ocular hypertension or open-angle glaucoma. Eur J Ophthalmol. 2012;22:34-44.

26. Goldberg I, Cunha-Vaz J, Jakobsen JE, et al. Comparison of topical travoprost eye drops given once daily and timolol $0.5 \%$ given twice daily in patients with open-angle glaucoma or ocular hypertension. J Glaucoma. 2001;10:414-422.

27. Gross RL, Peace JH, Smith SE, et al. Duration of IOP reduction with travoprost BAK-free solution. J Glaucoma. 2008;17:217-222.

28. Lewis RA, Katz GJ, Weiss MJ, et al. Travoprost $0.004 \%$ with and without benzalkonium chloride: a comparison of safety and efficacy. J Glaucoma. 2007;16:98-103.

29. Netland PA, Landry T, Sullivan EK, et al. Travoprost compared with latanoprost and timolol in patients with open-angle glaucoma or ocular hypertension. Am J Ophthalmol. 2001;132:472-484.

30. Caprioli J, Varma R. Intraocular pressure: modulation as treatment for glaucoma. Am J Ophthalmol. 2011;152:340-344. e2.

31. De Moraes CG, Hill V, Tello C, et al. Lower corneal hysteresis is associated with more rapid glaucomatous visual field progression. J Glaucoma. June 21, 2011. [Epub ahead of print.]

32. Lichter PR, Musch DC, Gillespie BW, et al. Interim clinical outcomes in the Collaborative Initial Glaucoma Treatment Study comparing initial treatment randomized to medications or surgery. Ophthalmology. 2001;108:1943-1953.
Clinical Ophthalmology

\section{Publish your work in this journal}

Clinical Ophthalmology is an international, peer-reviewed journal covering all subspecialties within ophthalmology. Key topics include: Optometry; Visual science; Pharmacology and drug therapy in eye diseases; Basic Sciences; Primary and Secondary eye care; Patient Safety and Quality of Care Improvements. This journal is indexed on

\section{Dovepress}

PubMed Central and CAS, and is the official journal of The Society of Clinical Ophthalmology (SCO). The manuscript management system is completely online and includes a very quick and fair peer-review system, which is all easy to use. Visit http://www.dovepress.com/ testimonials.php to read real quotes from published authors. 